\title{
Analisis Faktor yang Berhubungan dengan Higiene Sanitasi Rumah Makan di Wilayah Kerja Puskesmas Sarolangun Kabupaten Sarolangun
}

\section{Analysis of Factors Related to Restaurant Sanitation Hygiene in the Working Area of the Sarolangun Community Health Center, Sarolangun Regency}

\author{
Yulia Andriani ${ }^{1}$, Eti Kurniawati ${ }^{2}$, Parman ${ }^{3}$ \\ Jurusan Kesehatan Masyarakat, Sekolah Tinggi Ilmu Kesehatan Harapan Ibu Jambi ${ }^{1,2,3}$ \\ Email : yuliaandriani90789@gmail.com
}

\begin{abstract}
Food sanitation hygiene is an effort to control factors of food, people, places and equipment that can or may cause illness or health problems. Data from the Sarolangun District Health Office shows that Sarolangun District has the highest number of restaurants, namely 34 restaurants with 19 restaurants meeting the requirements and 7 restaurants that do not meet the requirements. This research is a quantitative study with a cross sectional approach. The research sample was 34 restaurants in the working area of the Sarolangun Health Center. The research instrument was a restaurant sanitation inspection sheet and a questionnaire. Data analysis using chi square test. The results showed that $21(63.6 \%)$ had proper hygiene and restaurant sanitation, $17(51.5 \%)$ respondents had high knowledge and $18(54.5 \%)$ respondents had positive attitudes. The results of the bivariate analysis showed that there was a relationship between knowledge $(p=0.032)$ and attitude $(p=0.027)$ with the sanitation hygiene of restaurants in the work area of the Sarolangun Community Health Center in 2020. For this reason, Sarolangun Puskesmas should conduct training on restaurant sanitation hygiene so that it can increase knowledge about restaurant hygiene sanitation restaurant owners so that they will apply restaurant sanitation hygiene. Conduct supervision and guidance regarding the implementation of restaurant sanitation hygiene, this is intended so that restaurant sanitation hygiene can be applied continuously so as to form habits that are in accordance with the restaurant sanitation hygiene requirements
\end{abstract}

Keywords: Sanitation Hygiene, Knowledge, Attitude

\begin{abstract}
ABSTRAK
Higiene sanitasi makanan merupakan salah satu upaya untuk mengendalikan faktor makanan, orang, tempat dan perlengkapan yang dapat atau mungkin menimbulkan penyakit atau gangguan kesehatan. Data Dinas Kesehatan Kabupaten Sarolangun menunjukkan bahwa Kecamatan Sarolangun memiliki jumlah rumah makan paling banyak yaitu 34 rumah makan dengan jumlah rumah makan yang memenuhi syarat sebanyak 19 dan 7 rumah makan tidak memenuhi syarat. Penelitian ini merupakan penelitian kuantitatif dengan pendekatan cross sectional. Sampel penelitian adalah rumah makan yang ada di wilayah kerja Puskesmas Sarolangun berjumlah 34 rumah makan. Instrumen penelitian adalah lembar inspeksi sanitasi rumah makan dan kuesioner. Analisa data menggunakan uji chi square. Hasil penelitian didapatkan sebanyak $21(63,6 \%)$ memiliki higiene sanitasi rumah makan memenuhi syarat, 17 (51,5\%) responden memiliki pengetahuan tinggi dan $18(54,5 \%)$ responden memiliki sikap positif. Hasil analisis bivariat menunjukkan bahwa ada hubungan antara pengetahuan $(\mathrm{p}=0,032)$ dan sikap $(\mathrm{p}=0,027)$ dengan higiene sanitasi rumah makan di wilayah kerja Puskesmas Sarolangun Tahun 2020. Untuk itu sebaiknya Puskesmas Sarolangun mengadakan pelatihan tentang higiene sanitasi rumah makan sehingga dapat meningkatkan pengetahuan tentang hygiene sanitasi rumah makan pemilik rumah makan sehingga akan menerapkan higiene sanitasi rumah makan. Melakukan pengawasan dan pembinaan mengenai penerapan higiene sanitasi rumah makan, hal ini dimaksudkan agar higiene sanitasi rumah makan dapat diterapkan secara terus menerus sehingga membentuk kebiasaan yang sesuai persyaratan higiene sanitasi rumah makan
\end{abstract}

Kata Kunci : Higiene Sanitasi, Pengetahuan, Sikap 


\section{PENDAHULUAN}

Penyakit yang ditularkan melalui makanan (food borne disease) merupakan penyakit yang menular atau keracunan yang disebabkan oleh agen mikroba atau agen yang masuk kedalam badan melalui makanan. Pada tahun 2017, berdasarkan data dari Direktorat Kesehatan Lingkungan dan Public Health Emergency Operating Center (PHEOC) kementerian kesehatan mencatat KLB keracunan pagan berjumlah 163 kejadian dan 7123 kasus (Kemenkes RI, 2018).

Menurut Peraturan Menteri Kesehatan Nomor 1096/Menkes/PER/VI/2011, higiene sanitasi makanan adalah upaya untuk mengendalikan faktor makanan, orang, tempat dan perlengkapannya yang dapat atau mungkin dapat menimbulkan penyakit atau gangguan kesehatan. Mengolah makanan yang baik harus memiliki enam prinsip higiene sanitasi makanan, diantaranya pemilahan bahan baku makanan, penyimpanan bahan makanan, pengolahan makanan, penyimpanan makanan jadi, pengangkutan makanan dan penyajian makanan, penerapan higiene sanitasi makanan dilakukan untuk mempertahankan dan memperbaiki kesehatan (Depkes RI, 2003).

Rumah makan/restoran di Indonesia sebagian besar masih belum mengerti betul perihal persyaratan higiene sanitasi yang erat hubungannya dengan kesehatan. Pada umumnya pengusaha rumah makan/restoran dalam menyelenggarakan usahanyahanya mementingkan segi komersial saja dan kurang memperhatikan persyaratan peraturan tentang kesehatan atau sanitasi tempat umum (Mukono, 2004).

Data Dinas Kesehatan Kabupaten Sarolangun tahun 2019 diketahui bahwa di Kabupaten Sarolangun, jumlah rumah makan yang ada sebanyak 188 rumah makan. Dilihat dari jumlah rumah makan yang paling tertinggi adalah Puskesmas Sarolangun yaitu sebanyak 33 rumah makan (Dinas Kesehatan Kabupaten Sarolangun, 2019). Puskesmas Sarolangun sudah melakukan inspeksi sanitasi rumah makan dan diperoleh hasil bahwa rumah makan yang memenuhi syarat di tahun 2019 sebanyak 19 rumah makan, yang tidak memenuhi syarat sebanyak 7 rumah makan dan yang belum dilakukan inspeksi higiene sanitasi sebanyak 8 rumah makan.

Pengelolaan makanan yang higienis ditentukan oleh beberapa faktor antara lain faktor lingkungan (bangunan dan lokasi, peralatan untuk proses pengelolaan,perabotan kerja, fasilitas sanitasi), faktor manusia (keadaan fisik tubuh dan pakaian yang dipakai, pengetahuan yang dimiliki, sikap atau pandangan hidup, perilaku atau tindakan yang biasa dikerjakan), faktor makanan (pemilihan bahan makanan, penyimpanan bahan makanan, pengelolaan makanan, penyimpanan makanan jadi, pengangkutan makanan, penyajian makanan) (Mukono, 2004). Oleh karena itu, pengusaha atau pemilik rumah makan mempunyai peranan penting dalam pengambilan keputusan dan tindakan untuk mewujudkan higiene sanitasi rumah makan yang memenuhi syarat kesehatan.

Berdasarkan survei awal yang dilakukan pada tanggal 13-14 Februari 2020 dengan turun langsung ke rumah makan dan melakukan observasi terhadap 10 rumah makan didapatkan hasil bahwa 6 rumah makan yang memenuhi syarat meliputi : bangunan tempat tinggal terpisah dengan rumah makan, lantai bersih dan tidak licin, tersedia tempat sampah dari bahan kedap air dan mempunyai tutup. Sedangkan 4 rumah makan yang tidak memenuhi syarat meliputi : tidak ada karyawan yang memakai baju kerja atau celemek, tidak tersedianya locker karyawan, tidak memiliki sertifikat higiene sanitasi rumah makan, dan terdapat lantai yang kotor dan licin.

Tujuan penelitian adalan untuk mengetahui faktor yang berhubungan denganhigiene sanitasirumah makan di wilayah Puskesmas Sarolangun, Kabupaten Sarolangun. 


\section{METODE}

Penelitian ini merupakan penelitian kuantitatif dengan rancangan desain penelitian Cross Sectional yang bertujuan untuk mengetahui analisis faktor yang berhubungan dengan higiene sanitasi rumah makan di wilayah kerja Puskesmas Sarolangun Kabupaten Sarolangun tahun 2020. Populasi penelitian adalah seluruh rumah makan yang ada di wilayah kerja Puskesmas Sarolangun. Sampel penelitian adalah pemilik rumah makan yang ada di wilayah kerja Puskesmas Sarolangun sebanyak 33. Penelitian ini telah dilakukan pada tanggal 21 Juni-4 Juli 2020. Teknik pengambilan sampel menggunakan teknik total populasi. Instrumen penelitian adalah lembar observasi hygiene sanitasi rumah makan dan kuesioner tentang pengetahuan dan sikap. Data diperoleh dengan observasi kondisi higiene sanitasi rumah makan menggunakan lembar inspeksi kepada pemilik rumah makan terkait variabel yang diteliti menggunakan kuesioner. Uji statistik yang digunakan yaitu uji statistic chi-square dan hasil penelitian di analisis secara univariat dan bivariat.

\section{HASIL DAN PEMBAHASAN}

Hasil analisis univariat menunjukkan bahwa 21 (63,6\%) memiliki higiene sanitasi rumah makan memenuhi syarat, 17 (51,5\%) responden memiliki pengetahuan tinggi dan $18(54,5 \%)$ responden memiliki sikap positif (Tabel 1). Hasil analisis bivariat menunjukkan bahwa ada hubungan antara pengetahuan $(\mathrm{p}=0,032)$ dan sikap $(\mathrm{p}=0,027)$ dengan higiene sanitasi rumah makan di wilayah kerja Puskesmas Sarolangun Tahun 2020 (Tabel 2).

Tabel 1. Gambaran pengetahuan,sikap dan higiene sanitasi rumah makan di wilayah kerja Puskesmas Sarolangun

\begin{tabular}{lcc}
\hline \multicolumn{1}{c}{ Variabel } & Jumlah & \% \\
\hline Higiene Sanitasi Rumah Makan & & \\
Tidak Memenuhi Syarat & 12 & 36,4 \\
Memenuhi Syarat & 21 & 63,6 \\
\hline Pengetahuan & 16 & 48,5 \\
Rendah & 17 & 51,5 \\
Tinggi & & \\
\hline Sikap & 15 & 45,5 \\
Negatif & 18 & 54,5 \\
Positif &
\end{tabular}

Tabel 2 Hubungan Pengetahuan dan Sikap dengan Higiene Sanitasi Rumah Makan di Wilayah Kerja Puskesmas Sarolangun Kabupaten Sarolangun

\begin{tabular}{|c|c|c|c|c|c|c|c|}
\hline \multirow{3}{*}{ Variabel } & \multicolumn{4}{|c|}{ Higiene Sanitasi Rumah Makan } & \multirow{2}{*}{\multicolumn{2}{|c|}{ Total }} & \multirow{3}{*}{ p-value } \\
\hline & \multicolumn{2}{|c|}{ Tidak MMS } & \multicolumn{2}{|c|}{ MMS } & & & \\
\hline & $\mathbf{n}$ & $\%$ & $\mathbf{n}$ & $\%$ & $\mathbf{n}$ & $\%$ & \\
\hline \multicolumn{8}{|l|}{ Pengetahuan } \\
\hline Rendah & 9 & 56,3 & 7 & 43,8 & 16 & 100,0 & \multirow{2}{*}{0,032} \\
\hline Tinggi & 3 & 17,6 & 14 & 82,4 & 17 & 100,0 & \\
\hline \multicolumn{8}{|l|}{ Sikap } \\
\hline Negatif & 9 & 60,0 & 6 & 40,0 & 15 & 100,0 & 0,027 \\
\hline Positif & 3 & 16,7 & 15 & 83,3 & 18 & 100,0 & \\
\hline
\end{tabular}


Hasil penelitian menunjukkan bahwa sebanyak $36,4 \%$ responden memiliki higiene sanitasi tidak memenuhi syarat dan sebanyak 63,6\% responden memiliki hygiene sanitasi rumah makan yang memenuhi syarat. Rumah makan merupakan salah satu fasilitas umum yang menyediakan makanan dan minuman yang banyak diminati oleh masyarakat, terkadang ada rumah makan yang tidak terlalu memperhatikan higiene dan sanitasi makanan mereka terutama pada saat menyediakan atau meyajikan makanan kepada konsumen. Rumah makan tentunya harus memenuhi standar persyaratan selain akan memberikan dampak bagi kesehatan juga mempunyai nilai ekonomi bagi pengusaha atau pengelola rumah makan itu sendiri. Rumah makan harus memenuhi persyaratan higiene dan sanitasi yang baik. Adapun persayaratan higiene dan sanitasi yang harus dipenuhi pedagang atau pengusaha rumah makan adalah lokasi dan bangunan, fasilitas sanitasi, dapur, ruang penyimpanan, bahan makanan dan makanan jadi, pengolahan makanan, penyimpanan bahan makanan dan makanan jadi, penyajian makanan jadi dan peralatan yang digunakan.

Pemilik rumah makan tidak menyediakan sabun dan lap pengering di toilet dikarenakan sudah menyediakan sabun dan lap di tempat cuci tangan. Jika ada pengunjung yang ingin mencuci tangan maka dilakukan di tempat cuci tangan yang sudah disediakan oleh pemilik rumah makan. Pemilik rumah makan tidak menyediakan loker karyawan dikarena karyawan hanya sedikit dan sebagian yang manjadi penjamah makanan adalah pemilik rumah makan itu sendiri sehingga tidak disediakan loker karyawan. Pemilik rumah makan tidak menyediakan tempat sampah di setiap ruangan dikarenakan tidak mengetahui bahwa disetiap ruangan harus tersedia tempat sampah begitu juga dengan tulisan higiene sanitasi, pemilik rumah makan tidak mengetahui bahwa di rumah makan harus dipasang tulisan higiene sanitasi bagi penjamah

Ketidaktahuan pemilik rumah makan tentang syarat higiene sanitasi rumah makan dikarenakan belum pernah mengikuti pelatihan higiene sanitasi rumah makan. Pemilik tidak mengikuti pelatihan dikarenakan Puskesmas belum mengadakan kegiatan pelatihan higiene sanitasi rumah makan. Tidak ada anjuran dan kegiatan pelatihan higiene sanitasi rumah makan membuat pemiliki rumah makan tidak mengikuti pelatihan. Penjamah makanan tidak menggunakan baju khusus dikarenakan pemilik rumah makan tidak menyediakan baju khusus penjamah, selain itu penjamah juga beranggapan bahwa baju yang dipakainya bersih sehingga tidak akan mempengaruhi sanitasi makanan. Penjamah makanan tidak melakukan check up penyakit khusus dikarenakan pemilik rumah makan tidak memberikan biaya untuk check up. Selain itu penjamah makanan dalam keadaan sehat sehingga tidak perlu melakukan check up penyakit khusus.

Puskesmas Sarolangun sudah melakukan isnpeksi sanitasi rumah makan dan diperoleh hasil bawa rumah makan yang memenuhi syarat di tahun 2019 sebanyak 19 rumah makan dan yang tidak memenuhi syarat ada 7 rumah makan. Namun puskesmas tidak melakukan monitoring dan evaluasi terhadap inspeksi rumah makan yang sudah dilakukan sehingga perilaku dari pemilik rumah makan juga tidak mengalami perubahan.

Berdasarkan hasil penelitian diperoleh nilai $\mathrm{p}$-value $=0,032$, sehingga dapat disimpulkan bahwa ada hubungan antara pengetahuan dengan higiene sanitasi rumah makan di wilayah kerja Puskesmas Sarolangun. Dengan kata lain semakin tinggi pengetahuan yang dimiliki oleh responden maka semakin baik penerapan higiene sanitasi rumah makan. 
Hasil penelitian ini sejalan dengan penelitian Herdianti, Wiwin Trioktoriana \& Noviyanti (2019) menunjukkan bahwa aada hubungan antara pengetahuan dengan higiene sanitasi rumah makan $(\mathrm{p}=0,002)$ (Herdianti, Trioktoriana, \& Noviyanti, 2019). Hasil penelitian Maryam Maghafirah, Sukismanto \& Merita Eka Rahmuniyati (2018) di Yogyakarta yang menunjukkan bahwa ada hubungan antara pengetahuan dengan higiene sanitasi penjamah makanan di sepanjang Jalan Raya Tajem Maguwoharjo Yogyakarta (0,009) (Maghfirah, Sukismanto, \& Rahmuniyati, 2018). Hasil penelitian Julia Ulfa, Subakir dan Sugiarto (2020) menunjukkan bahwa ada hubungan antara pengetahuan dengan higiene sanitasi (Ulfa, Subakir, \& Sugiarto, 2020)

Hasil penelitian ini menunjukkan ada hubungan antara pengetahuan dengan higiene sanitasi rumah makan. Semakin baik pengetahuan yang dimiliki oleh responden maka semakin baik praktik higiene sanitasi rumah makan, begitu sebaliknya semakin kurang baik pengetahuan yang dimiliki oleh responden maka semakin kurang baik praktik higiene sanitasi rumah makan. Pada penelitian ini ditemukan bahwa masih kurangnya wawasan responden terkait komponen-komponen yang harus dilengkapi atau diterapkan agar higiene sanitasi rumah makan memenuhi syarat kesehatan.

Hasil penelitian menunjukkan bahwa responden yang memiliki pengetahuan tinggi maka semakin baik penerapan higiene sanitasi rumah makan. Misalnya responden mengetahui lokasi rumah makan tidak berada pada pencemaran debu, asap, dan cemaran lainnya, bangunan terpisah dengan tempat tinggal, pencahayaan harus tersebar merata disetiap ruangan, pembuangan air limbah harus mengalir dengan lancer dan tempat tandon air mempunyai tutup.

Sedangkan responden yang memiliki pengetahuan yang rendah maka akan kurang baik dalam melakukan penerapan higiene sanitasi rumah makan. Misalnya responden tidak mengetahui bahwa lubang ventilasi seharusnya dipasang kawat kassa untuk menghindari serangga atau tikus, toilet seharusnya tidak boleh berhubungan langsung dengan dapur, disetiap ruangan harus terdapat tempat sampah, mencuci peralatan menggunakan air yang mengalir, dicuci dengan tiga kali pengulangan atau menggunakan tiga bak pencuci, makanan jadi harus disimpan secara tertutup, ketika menyajikan makanan pun harus dengan cara membawa dan menyajikannya secara tertutup, perlunya pemilik untuk mengikuti pelatihan higiene sanitasi serta perlunya karyawan/penjamah makanan untuk memeriksakan kesehatan tiap 6 bulan sekali.

Pada saat melakukan inspeksi sanitasi rumah makan, petugas puskesmas juga melakukan konseling kepada pemilik rumah makan. Oleh karena itu perlunya memperluas wawasan atau pengetahuan responden terkait higiene sanitasi rumah makan. Penambahan wawasan tersebut dapat dilakukan dengan cara memberikan atau menambahkan wawasan responden dengan rutin menyampaikan apa saja persyaratan higiene sanitasi rumah makan yang harus dipenuhi oleh pemilik usaha rumah makan yang telah dijabarkan dalam keputusan menteri kesehatan nomor 1098/2003 tentang persyaratan higiene sanitasi rumah makan. Dari persyaratan tersebut responden bisa mengetahui apa saja yang seharusnya dilakukan untuk menjaga kebersihan diri dan peralatan serta fasilitas dari rumah makan tersebut.

Untuk meningkatkan pengetahuan pemilik rumah makan tentang higiene sanitasi rumah makan sebaiknya puskesmas mengadakan pelatihan tentang higiene sanitasi rumah makan sehingga dapat meningkatkan pengetahuan tentang hygiene sanitasi rumah makan pemilik rumah makan sehingga akan menerapkan higiene sanitasi rumah makan. 
Berdasarkan hasil penelitian diperoleh nilai $\mathrm{p}$-value $=0,027$, sehingga dapat disimpulkan bahwa ada hubungan antara sikap dengan higiene sanitasi rumah makan di wilayah kerja Puskesmas Sarolangun. Dengan kata lain semakin positif sikap yang dimiliki oleh responden maka semakin baik penerapan higiene sanitasi rumah makan.

Hasil penelitian ini sejalan dengan penelitian Icca Stella Amalia, Eni Rohaeni \& Deasy Muriawati (2015) di Kecamatan Kadugede Kabupaten Kuningan diperoleh hasil bahwa ada hubungan antara sikap dengan praktik higiene sanitasi penjamah makanan ( $\mathrm{p}=0,022)$ (Amalia, Rohaeni, \& Muriawati, 2015). Hasil penelitian ini sejalan dengan penelitian Fatmawati (2013) di sekitar wisata Pantai Logending Kabupaten Kebumen diperoleh hasil bahwa ada hubungan antara sikap dengan praktik sanitasi pada pedagang makanan ( $\mathrm{p}=0$,001) (Fatmawati \& Ali, 2013).

Hasil penelitian menunjukkan bahwa sikap berhubungan dengan higiene sanitasi rumah makan. Responden tidak menerapkan higiene sanitasi rumah makan dikarenakan memiliki sikap negatif. Sikap negatif yang dimiliki oleh responden dikarenakan responden belum mengetahui penerapan higiene sanitasi yang baik dan benar. Responden belum mendapatkan pelatihan tentang higiene sanitasi rumah makan menyebabkan tingkat pengetahuan tentang higiene sanitasi rumah makan juga rendah. Rendahnya pengetahuan yang dimiliki oleh responden berpengaruh terhadap sikap dalam penerapan higiene sanitasi rumah makan. Sesuai dengan teori (Notoatmodjo, 2010) menyatakan bahwa sikap seseorang berbanding lurus dengan pengetahuan yang dimiliki oleh orang tersebut. Semakin tinggi pengetahuan maka sikap yang dimilikinya semakin baik, begitu sebaliknya semakin rendah pengetahuan yang dimiliki seseorang maka semakin kurang baik sikap yang dimiliki orang tersebut. Selain itu sikap pemilik rumah makan juga dipengaruhi oleh faktor lingkungan, pengalaman serta pendidikan yang dimilikinya (Notoatmodjo, 2010).

Penjamah makanan harus mengikuti pelatihan yang tepat dalam prinsipprinsip dasar keamanan pangan dan aturan kebersihan pribadi dalam rangka pembentukan sikap, sehingga dapat meningkatkan praktik mereka dalam penanganan makanan. Praktik higiene sanitasi yang dilakukan oleh responden merupakan cerminan dari sikap responden yang mendukung atau tidak mendukung terhadap higiene sanitasi rumah makan. Sehingga dapat disimpulkan bahwa sikap mempengaruhi langsung terhadap praktik higiene sanitasi yang dimiliki oleh responden. Semakin baik sikap maka semakin baik pula praktik higiene sanitasinya.

Sedangkan berdasarkan hasil penelitian yang dilakukan oleh peneliti, responden yang memiliki sikap positif akan melakukan perilaku yang baik pula terhadap penerapan higiene sanitasi rumah makan/restoran. Misalnya pada hasil inspeksi kesehatan lingkungan diketahui bahwa responden memiliki sikap yang positif seperti, ruang makan selalu bersih, lantai bersih, tidak licin dan kering, ventilasi tersedia dan berfungsi dengan baik, pencahayaan tersebar merata disetiap ruangan, sampah dikumpulkan dan diangkut tiap 24 jam, perlengkapan dan peralatan makan selalu bersih tersedia air cuci tangan yang mencukupi, tempat peragaan makanan jadi tertutup sehingga terhindar dari lalat, makanan disajikan pada tempat yang bersih, setiap karyawan/penjamah makanan berperilaku bersih dan berpakaian rapi.

Untuk responden yang memiliki sikap negatif seperti, tidak disediakan pakaian khusus kerja bagi karyawan, cara membawa dan menyajikan makanan tidak tertutup, sebelum bekerja terkadang lupa untuk mencuci tangan, apabila batuk/bersin tidak menutup mulut dengan sapu tangan. Jika sikap negatif tersebut dibiarkan saja, maka akan berpengaruh terhadap hasil olahan makanan dan kesehatan konsumen. Responden pun akan tetap merasa hal negatif yang dilakukannya adalah hal yang 
normal atau tidak apa-apa jika bersikap seperti itu sehingga akan semakin sulit nantinya untuk mengubah sikap negatif responden.

Hasil penelitian juga menunjukkan bahwa responden yang memiliki sikap negatif tetapi higiene sanitasi rumah makan memenuhi syarat yaitu sebanyak 6 $(40,0 \%)$ orang. Hal tersebut dikarenakan pemilik rumah makan selalu melakukan pengawasan terhadap penjamah makanan sehingga karena merasa diawasi maka penjamah makanan selalu mengikuti aturan yang sudah ditetapkan oleh pemilik rumah makan.

Untuk meningkatkan sikap higiene sanitasi pemilik rumah makan maka diperlukan dorongan atau dukungan yang lebih kuat dari tenaga kesehatan lingkungan untuk mengadvokasi/mengajak pemilik rumah makan agar dapat merubah sikap yang negatif tersebut berubah menjadi sikap yang baik terhadap penerapan higiene sanitasi rumah makan. Dan diharapkan kepada Dinas Kesehatan Kabupaten Sarolangun perlu meningkatkan pentingnya higiene sanitasi rumah makan dengan cara membentuk suatu peraturan mengenai perizinan rumah makan. Menurut Sugiarto, pemberian edukasi dapat meningkatkan perilaku seseorang menjadi lebih baik (Sugiarto, Berliana, Yenni, \& Wuni, 2019)

\section{KESIMPULAN}

Berdasarkan hasil penelitian diketahui bahwa faktor yang berhubungan dengan higiene sanitasi rumah makan di wilayah kerja Puskesmas Sarolangun adalah pengetahuan dan sikap.

\section{SARAN}

Untuk itu diharapkan kepada Puskesmas untuk mengadakan pelatihan tentang higiene sanitasi rumah makan secara rutin sehingga dapat meningkatkan pengetahuan dan wawasan tentang hygiene sanitasi rumah makan pemilik rumah makan sehingga akan menerapkan higiene sanitasi rumah makan.

\section{DAFTAR PUSTAKA}

Amalia, I. S., Rohaeni, E., \& Muriawati, D. (2015). Hubungan Pengetahuan dan Sikap dengan Praktik Higiene Sanitasi Penjamah Makanan di Kecamatan Kadungede Kabupaten Kuningan Tahun 2013. Jurnal Ilmu-Ilmu Kesehatan Bhakti Husada Kuningan, 4(2), 52-57.

Depkes RI. (2003). Keputusan Menteri Kesehatan Nomor 1098/MENKES/SK/VII/2003. Persyaratan Hgiene Sanitasi Rumah Makan dan Restoran. Jakarta: Departemen Kesehatan RI.

Dinas Kesehatan Kabupaten Sarolangun. (2019). Profil Kesehatan Kabupaten Sarolangun Tahun 2019. Jambi: Dinas Kesehatan Kabupaten Sarolangun.

Fatmawati, S., \& Ali, R. E. (2013). Perilaku Higiene Pengolah Makanan Berdasarkan Pengetahuan Tentang Higiene Mengolah Makanan Dalam Penyelenggaraan Makanan di Pusat Pendidikan dan Latihan Olahraga Pelajar Jawa Tengah. Jurnal Pangan Dan Gizi, 4(8).

Herdianti, Trioktoriana, \& Noviyanti. (2019). Perilaku dan Karakteristik Penjamah Makanan terhadap Higiene Sanitasi Makanan pada Rumah Makan. Kampurui 
Jural Kesehtan Kesehatan Masyarakat, 1(17), 17-25.

Kemenkes RI. (2018). Profil Kesehatan Indonesia. Jakarta: Kementerian Kesehatan Republik Indonesia.

Maghfirah, M., Sukismanto, \& Rahmuniyati. (2018). Hubungan Pengetahuan dan Sikap dengan Praktik Hygiene Sanitasi penjamah Makanan di Sepanjang Jalan Raya Tajem Maguwoharjo Yogyakarta Tahun 2017. Jurnal Formil KesMas Respati, 3(1), 15-22.

Mukono. (2004). Higiene Sanitasi Hotel dan Restoran. Surabaya: Pusat Penerbitan dan Percetakan Unair.

Notoatmodjo, S. (2010). Ilmu Perilaku Kesehatan. Jakarta: Rineka Cipta.

Sugiarto, Berliana, N., Yenni, M., \& Wuni, C. (2019). Peningkatan Pengetahuan Siswa tentang Cuci Tangan yang Baik dan Benar di SDN 37/I Kecamatan Bajubang. Jurnal Pengabdian Harapan Ibu (JPHI), 1(2), 59-64.

Ulfa, J., Subakir, \& Sugiarto. (2020). Faktor-Faktor Yang Berhubungan Dengan Hygiene Sanitasi Indutri Pengerajin Kue. Journal of Healthcare Technology and Medicine, 6(2), 837-849. Retrieved from https://jurnal.uui.ac.id/index.php/JHTM/article/view/1040/521 